\title{
A Machine Learning Approach to Metallogenic Controls on Precious Metal Abundances in Mantle Plumes of the Atlantic
}

JORDAN J LINDSAY*1, HANNAH S R HUGHES ${ }^{1}$, JENS C Ø ANDERSEN $^{1}$, CHRIS M YEOMANS ${ }^{1}$, IAIN MCDONALD ${ }^{2}$,

${ }^{1}$ Camborne School of Mines, University of Exeter, Penryn

Campus, Penryn, Cornwall UK (*j1731@exeter.ac.uk)

${ }^{2}$ School of Earth and Ocean Sciences, Main Building,

Cardiff University, Park Place, Cardiff, UK

Platinum-group element (PGE) deposits are typically associated with intraplate (e.g. plume-derived) magmatism and thick continental cratons [1]. While crustal magmatic processes ultimately underpin the mineralisation process, it is unclear what dictates the fertility of mantle-derived magmas (according to starting composition and melting conditions). For example, subduction may enrich the sub-continental lithospheric mantle (SCLM) in precious metals via magmatic/metasomatic processes [2] and contaminate magmas that ascend from mantle plumes. Such contamination is expressed in the geochemistry. In the North Atlantic Igneous Province (NAIP), magmas systematically decrease in $\mathrm{Pt} / \mathrm{Pd}$ with time [3], which is proposed to reflect the shifting geodynamic environment (and consequent changes in metal budget) of the melting environment across the transition from continental to oceanic rifting. We explore if the Paraná-Etendeka Large Igneous Province (PELIP) in the South Atlantic, which displays a similar geodynamic development, also carries this distinctive $\mathrm{Pt} / \mathrm{Pd}$ trend.

The integration of dimensionality reduction (Principal Component Analysis and t-SNE [4]) and machine learning algorithms (MLA; by $k$-means clustering) into the analysis of the NAIP geochemical data set further supports the role of SCLM in PGE concentrations. This study shows that Pt and $\mathrm{Pd}$ are independent variables that are disassociated from all other major and trace elements (which would otherwise be interpreted in terms of magmatic fractionation via partial melting/crystallisation). We present new MLA analysis of a larger data set from the PELIP to test variations and clustering in the geochemistry, assess if a similar decoupling of Pt and Pd occurs, and test the spatial controls on this disassociation.

[1] Zhang et al (2008) Earth Sci. Rev., 86, 145-174. [2] Griffin et al. (2013) Nat. Geosci, 6 (11), 905-910. [3] Hughes et al. (2015) Lithos, 233, 89-110. [4] van der Maaten \& Hinton (2008) J. Mach. Learn. Res., 9, 2579-26 